\title{
Effect of iron and nickel substitution on the piezoelectric properties of PZT type ceramics
}

\author{
C. Miclea ${ }^{*}$, C. Tanasoiu, C.F. Miclea, A. Gheorghiu ${ }^{1}$, V. Tanasoiu, F.N. Sima \\ National Institute for Materials Physics, Bucharest-Magurele, ROMANIA \\ ${ }^{1}$ Hyperion University, Str. Calarasi 169, sector 3, Bucharest, ROMANIA
}

\begin{abstract}
The effect of Fe and Ni doping on piezoelectric properties of a soft type piezoelectric material was investigated. The materials composition was as follows: $\mathrm{Pb}_{0.95} \mathrm{Bi}_{0.03} \mathrm{Nb}_{0.02} \mathrm{Zr}_{0.51} \mathrm{Ti}_{0.49-\mathrm{x}} \mathrm{M}_{\mathrm{x}} \mathrm{O}_{3}$, where $\mathrm{M}$ stands for the transitional metals $\mathrm{Fe}$ or $\mathrm{Ni}$ and $\mathrm{x}=0$; $0.02 ; 0.04 ; 0.06 ; 0.08 ; 0.10$. The materials were prepared by the conventional ceramic technique, using high purity oxides, mixed in a planetary ball mill for 3 hours and double calcined at $850{ }^{\circ} \mathrm{C}$ and $900{ }^{\circ} \mathrm{C}$ for 2 hours, with an intermediate milling of 4 hours and a final milling of 48 hours in order to get a final powder with crystallites in the nanometric range. X-ray diffractograms showed that compounds were completely formed and they were situated in the nanometric range with an average crystallite size of about $95 \mathrm{~nm}$. The pressed and sintered samples of these materials showed maximum densification of about $98.5 \%$ of TD at an optimum sintering temperature of $1200{ }^{\circ} \mathrm{C}$ for both types of materials. The optimum amounts of doping for both types of transitional elements were situated somewhere around $\mathrm{x}=0.06$ with better results for nickel doped samples. Thus the maximum density for 0.06 nickel doped material was $7.87 \mathrm{~g} / \mathrm{cm}^{3}$ while for iron doped one it was only $7.80 \mathrm{~g} / \mathrm{cm}^{3}$. The piezoelectric properties followed consequently the same trend. Thus the electromechanical coupling factor $\mathrm{k}_{\mathrm{p}}$ for 0.06 nickel doped samples was 0.665 while for the correspondingly iron doped ones it was 0.638 . The relative dielectric constant was about 4050 for nickel doped samples and 3400 for iron doped ones. The corresponding values for the charge constant $\mathrm{d}_{33} \mathrm{were} 625 \mathrm{pm} / \mathrm{V}$ and 530 $\mathrm{pm} / \mathrm{V}$ respectively. These results were discussed in terms of the positions occupied by Ni and Fe into the lattice, the type of vacancies created by this and the shift of the morphotropic phase boundary.
\end{abstract}

Keywords: PZT; Perovskite; Piezoelectric properties; Dielectric properties; Sintering,

\section{Introduction}

At present there is an increasing demand for high quality piezoelectric materials used for the fabrication of the piezoelectric transducers for various applications in the field of sensors and actuators for fine displacement systems, especially in microrobotics or microelectromechanical systems.

Actuators make use of the direct expansion of piezoelectric materials and therefore for such applications there is a need for piezomaterials with high displacement constant $d^{1-7}$. Moreover, during the last years another striking application of the reverse piezoelectric effect was developed in the field of micromotors ${ }^{8-11}$, in large demand today as tiny motors for office equipment and microrobotics. Such piezoelectric micromotors are superior in the milimetric-size motor area to any other motors because their efficiency is completely insensitive to size. They can work with the same efficiency at low or high speed still retaining higher torque, have excellent controllability and fine position resolution. Do not require gear mechanism, are very quiet in operation and are not affected by the external magnetic and radioactive fields. Therefore, piezoelectric materials with large charge constant $d$ for such applications become imperative and the present investigation was conducted toward obtaining new PZT type materials with large $d$ constant and still having high electromechanical coupling coefficient able to be used for actuators and micromotors sensors and transducers.

\section{Experimental}

The materials investigated in the present work were a soft type PZT material doped with nickel and iron and having the general chemical formula: $\mathrm{Pb}_{0.95} \mathrm{Bi}_{0.03} \mathrm{Nb}_{0.02} \mathrm{Zr}_{0.51} \mathrm{Ti}_{0.49-\mathrm{x}} \mathrm{M}_{\mathrm{x}} \mathrm{O}_{3}$, where $\mathrm{M}$ stands for the transitional metal $\mathrm{Ni}$ or $\mathrm{Fe}$ and $0.00 \leq \mathrm{x} \leq 0.10$. The raw materials used for the experiment were oxides of p.a. purity. The materials were processed by the conventional ceramic technique with the following detailed data: six charges of each dopant $\mathrm{Ni}$ and $\mathrm{Fe}$ were prepared, corresponding to $\mathrm{x}=0.00 ; 0.02 ; 0.04$; $0.06 ; 0.08$ and 0.10 respectively. The stoichiometric amounts of oxides were wet mixed for $3 \mathrm{~h}$ by means of a planetary ball mill, in agate vials of $500 \mathrm{ml}$ capacity, using agate balls of about $10 \mathrm{~mm}$ diameter in a weight ratio: ball/oxides/acetone of 100/100/250. The mixed slurries were dried with continuous agitation on electrical plates, manually crushed and sieved and then double calcined at $850{ }^{\circ} \mathrm{C}$ and $950{ }^{\circ} \mathrm{C}$ respectively for 2 $\mathrm{h}$ with an intermediate milling of $4 \mathrm{~h}$ and a final milling of 48 hours. BET measurements of the final milled

* Corresponding author: Prof. Cornel Miclea, E-mail: cmic@infim.ro 
powders gave an average specific surface area between $10-12 \mathrm{~m}^{2} / \mathrm{g}$ corresponding to an average particle diameter of about 90-100nm. Disc shaped samples of $15 \mathrm{~mm}$ diameter and about $2 \mathrm{~mm}$ thick were next uniaxially pressed from these powders in a steel die at a pressure of about $50 \mathrm{MPa}$. The pressed samples were then sintered in dense alumina crucibles at temperatures between 1050 and $1300{ }^{\circ} \mathrm{C}$ for $4 \mathrm{~h}$. The density of each sintered sample was determined by Archimede's method. Next, the sintered samples were processed by grinding on a mechanically grinding machine up to a final dimension of $10 \mathrm{~mm}$ diameter and $1 \mathrm{~mm}$ thick. After ultrasonically cleaning and thermally recovery at $700{ }^{\circ} \mathrm{C}$ for $1 \mathrm{~h}$, the samples were silver electroded on both plan parallel surfaces and poled in a silicon oil bath at $220{ }^{\circ} \mathrm{C}$ under an electric field of $30 \mathrm{KV} / \mathrm{cm}$ and slowly cooled down to $80{ }^{\circ} \mathrm{C}$ under electric field after which the electric field was cut off and the samples taken out from the poling device. Piezoelectric properties were measured $24 \mathrm{~h}$ after poling by resonance spectroscopy using a HP 4194A Impedance gain/phase analyzer.

\section{Results and discussion}

Fig. 1 shows an example of the X-ray spectrum of a Ni doped calcined powder. As can be seen the PZT phase with perovskite structure is well formed, indicating that the PZT material synthesis was completely achieved. X-ray diffractograms were made for all powders investigated, but they are not shown here because they were entirely similar to this one.

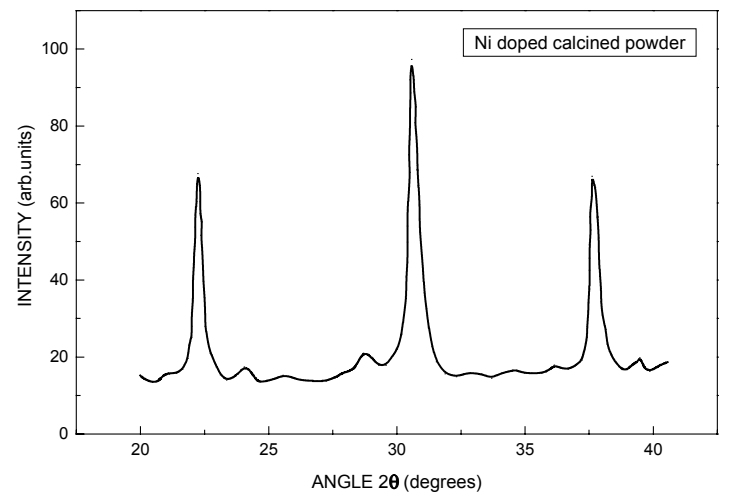

Fig. 1 X-ray diffractogram of the $0.06 \mathrm{Ni}$ doped calcined powder sample

Figures 2 and 3 illustrate the behavior of the densities of sintered samples as a function of the sintering temperature for all composition doped with $\mathrm{Ni}$ (fig. 2) and $\mathrm{Fe}$ (fig. 3) respectively.

One can see that for both types of composition there is an optimum sintering temperature centered on 1200

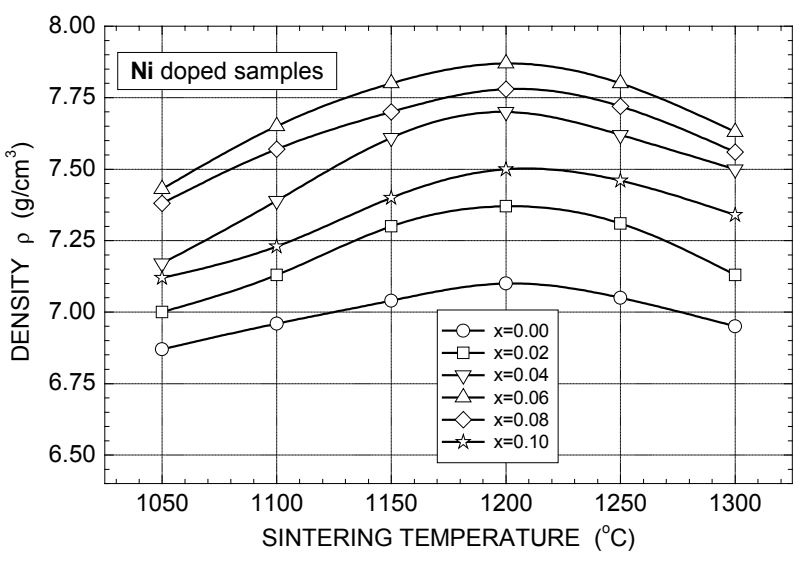

Fig. 2 The dependence of the density on the sintering temperature for $\mathrm{Ni}$ doped samples

${ }^{\circ} \mathrm{C}$ where the densities reach a maximum regardless the amount of dopant. With increasing the dopant amount $x$ the densities increase, reaching the highest values for compositions with $\mathrm{x}=0.06$ and then decreasing again.

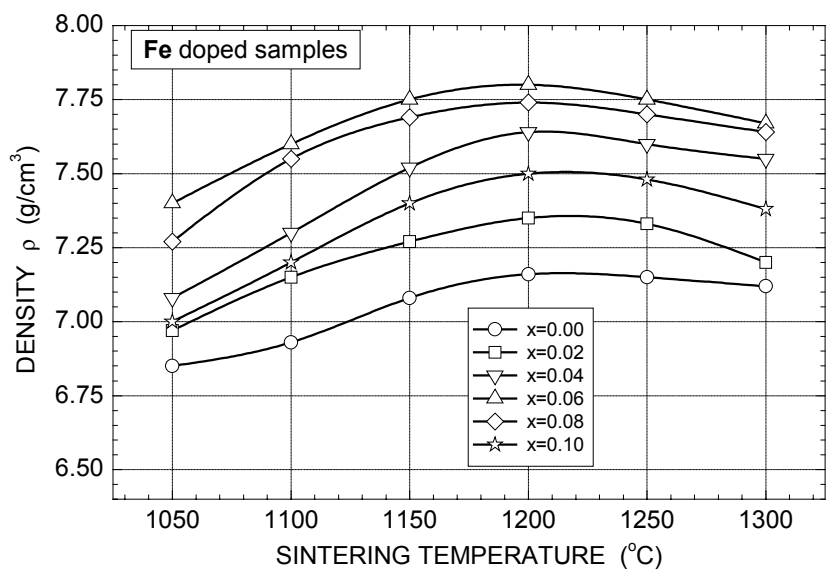

Fig. 3 The dependence of the $0.06 \mathrm{Fe}$ doped calcined powder sample

This behavior is well illustrated in the graph from fig. 4 where one can see the maximum densities of $7.87 \mathrm{~g} / \mathrm{cm}^{3}$ and $7.80 \mathrm{~g} / \mathrm{cm}^{3}$ for the $\mathrm{Ni}$ and $\mathrm{Fe}$ doped samples respectively, values which correspond to about 98.5 and $97.5 \%$ respectively of the theoretical density (if 8 $\mathrm{g} / \mathrm{cm}^{3}$ is taken as the right figure for the theoretical density of a PZT material ${ }^{12}$ ). These values would be even slightly higher if the theoretical density should be considered as $7.95 \mathrm{~g} / \mathrm{cm}^{3}{ }^{13}$ or $7.98 \mathrm{~g} / \mathrm{cm}^{314}$.

Such high values for the densities indicate that the sintered samples are fully densified with well-formed crystallites and rather poreless. This assertion is fully sustained by the fracture SEM images from fig. 5 made on $0.06 \mathrm{Ni}$ and $0.06 \mathrm{Fe}$ doped samples with the highest densities. 


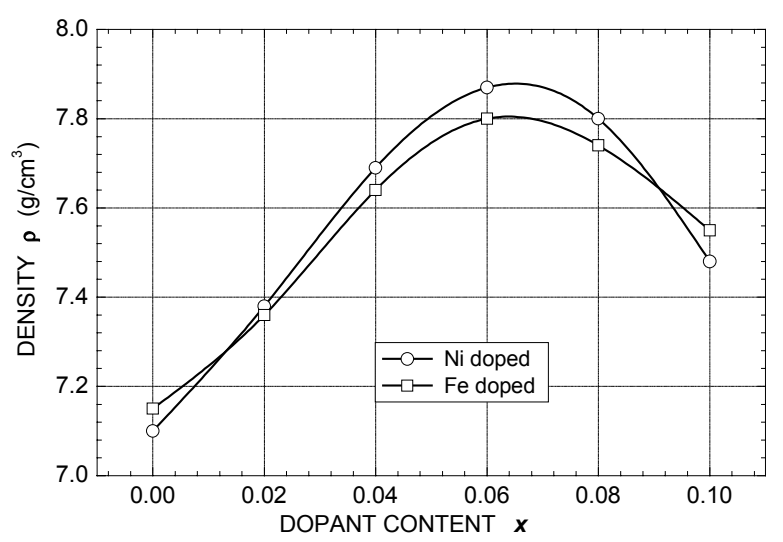

Fig. 4 The behavior of the maxim values of the density as a function of the dopant amount for $\mathrm{Ni}$ and $\mathrm{Fe}$ doped samples, sintered at $1200{ }^{\circ} \mathrm{C}$

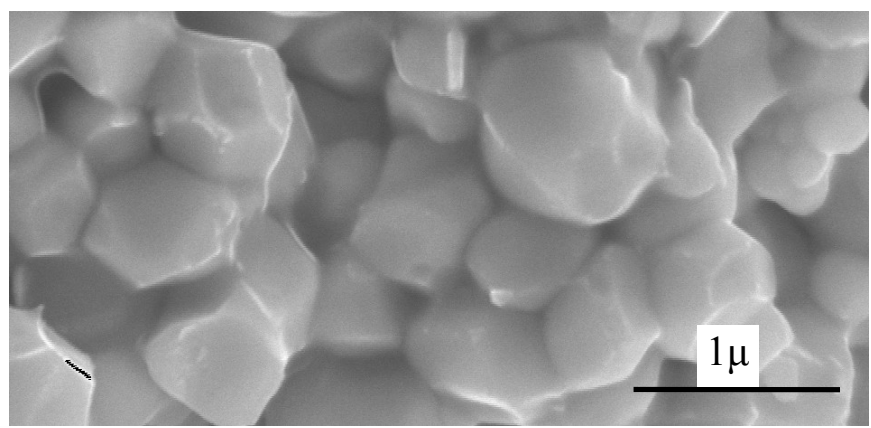

a)

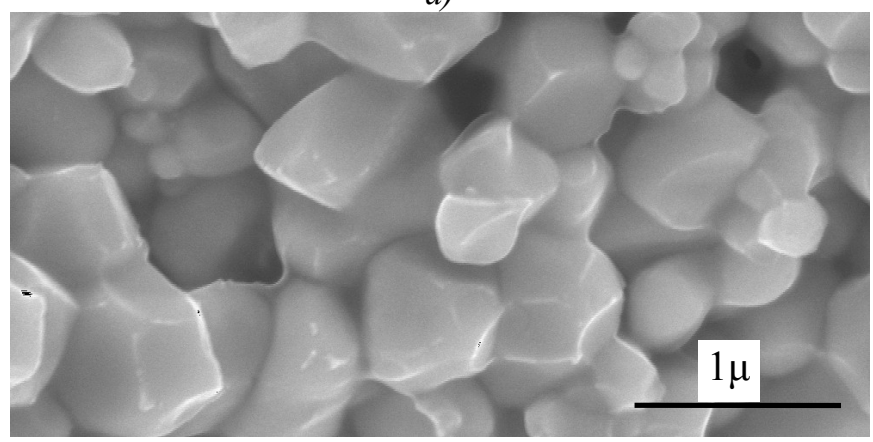

b)

Fig. 5 Fracture SEM images of the sintered samples doped with $0.06 \mathrm{Ni}$ (a) and $0.06 \mathrm{Fe}$ (b) respectively

One can see the lack of pores, and the well formed submicronic crystallites. One may expect the best piezoelectric properties for these samples as will be confirmed further.

The decrease of the densities for samples with $\mathrm{x}>0.06$ could possible be explained by a slight inhibiting effect of the dopants for higher concentrations. Fig. 6 shows a micrograph of a $\mathrm{Fe}$ doped sintered sample with $\mathrm{x}=0.10$ where the crystallites are smaller and some pores are present. The piezoelectric properties were determined only on samples with maximum densities, i.e. the samples sintered at $1200{ }^{\circ} \mathrm{C}$.

One can see that $k_{p}$ reaches maximum values of 0.665

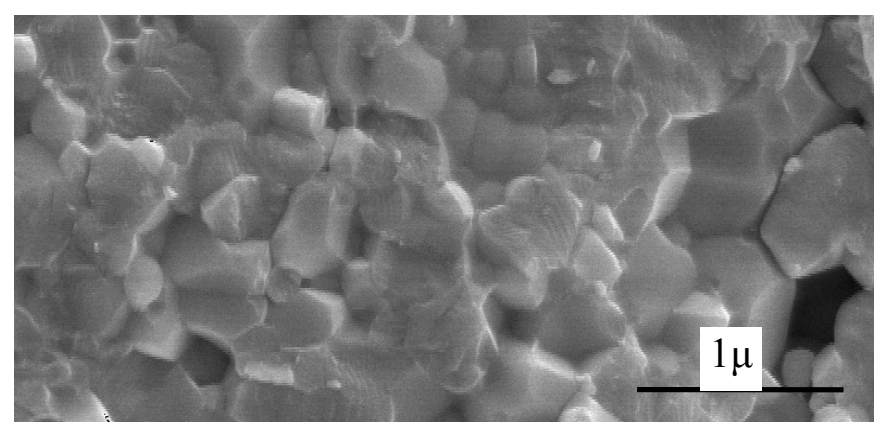

Fig. 6 Fracture SEM image of a sample doped with $0.10 \mathrm{Fe}$

Fig. 7 shows the dependence of the planar coupling coefficient $k_{p}$ on the dopant concentration.

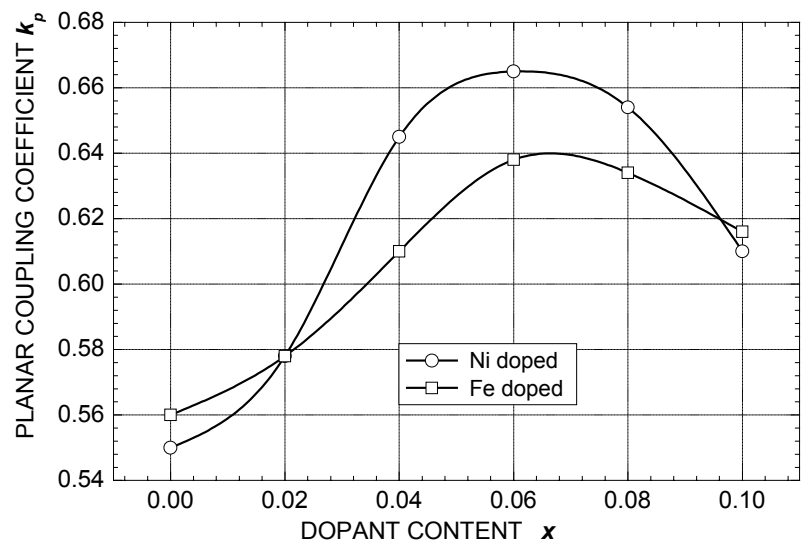

Fig. 7 The dependence of the planar coupling factors of $\mathrm{Ni}$ and Fe doped samples on the dopant concentration

and 0.638 for the compositions with $\mathrm{x}=0.06$ both for $\mathrm{Ni}$ and Fe doped samples respectively. The same trends and behaviors were recorded for charge constant $d_{33}$ and dielectric permitivitty $\varepsilon_{r}$ either as shown in fig 8 and 9 .

A remarkable thing about these graphs is the high values of the constants mentioned before. Thus, for Ni doped samples, a maxim value of about $625 \mathrm{pm} / \mathrm{V}$ for $d_{33}$ was measured and $530 \mathrm{pm} / \mathrm{V}$ for Fe doped samples respectively. Such values can be considered very high for an ordinary doped PZT material and this fact makes such materials excellent candidates for actuators or micromotors.

At the same time the dielectric permitivities at room temperature reach also high values of nearly 4050 and 3400 for $\mathrm{Ni}$ and $\mathrm{Fe}$ doped samples respectively. This might be the result of a slight decrease of the Curie temperature. In fact all these experimental results can be explained by the assumption that the presence of the dopants gives rise to A vacancies into the PZT lattice with the direct consequence of rising the dielectric constant, the piezoelectric coupling factor and the charge constant ${ }^{15}$. This is consistent with the ionic 
radius rule. Thus $\mathrm{Ni}^{2+}$ has an ionic radius of $0.69 \AA$ and enters the $\mathrm{Ti}^{4+}$ position which has a radius of $0.68 \AA$.

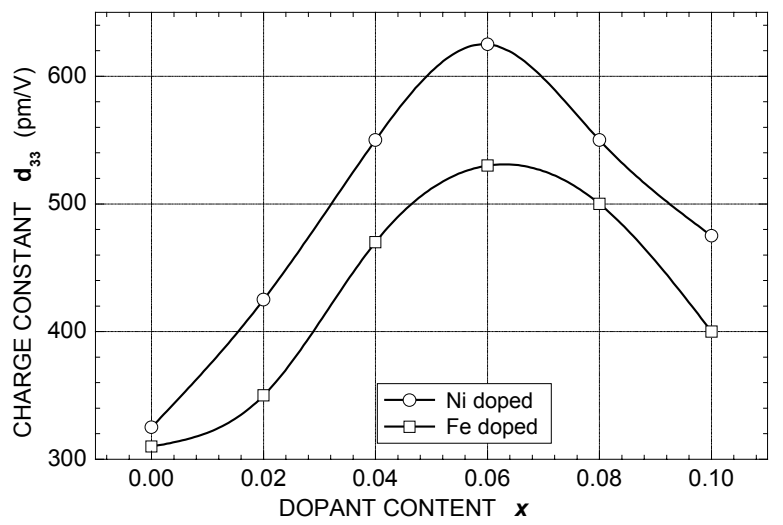

Fig. 8 The dependence of the charge constant $d_{33}$ of $\mathrm{Ni}$ and Fe doped samples on the dopant concentration

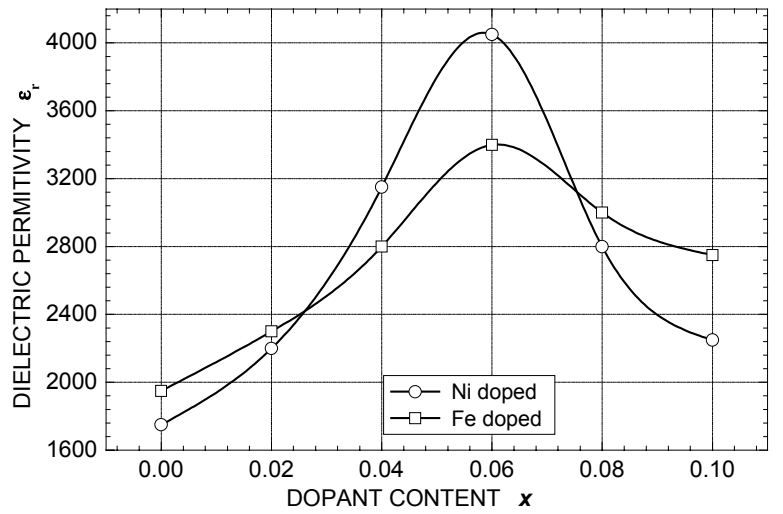

Fig. 9 The dependence of the relative dielectric permitivity of $\mathrm{Ni}$ and $\mathrm{Fe}$ doped samples on the dopant concentration

On the other hand $\mathrm{Fe}^{2+}$ with its $0.75 \AA$ ionic radius, most probably enters $\mathrm{Zr}^{4+}$ position with $0.80 \AA$ ionic radius. Thus the tetragonal and the rhombohedral phases are equally affected by the presence of $\mathrm{Ni}$ and $\mathrm{Fe}$ and forms a new morphotropic phase boundary probably at $\mathrm{x}=0.06^{16}$, where the piezoelectric properties are subsequently enhanced because of the increased easy of reorientation during poling ${ }^{17}$. A shift of $\mathrm{R}$ and $\mathrm{T}$ phases is also possible by the new distribution of $\mathrm{Ni}$ and $\mathrm{Fe}$ ions into the lattice. Such a shift forms stronger piezoelectric effects by the easiness of domain reorientation. Within the $\mathrm{R}$ side the number of $180^{\circ}$ domains is greater and they are more easily aligned along the poling field direction than the $90^{\circ}$ domains which switch harder. In thus way it seems easy to assume a higher degree of alignment of dipoles after removal of the field and consequently higher piezoelectric parameters for the $\mathrm{Ni}$ doped compositions.

\section{Summary}

A soft type PZT material was doped with nickel and iron within a narrow compositional range. The materials were prepared by the conventional ceramic technique and were sintered at temperatures up to 1300 ${ }^{\circ} \mathrm{C}$. The optimum sintering temperature proved to be $1200{ }^{\circ} \mathrm{C}$ for both types of doped samples. The samples sintered at this temperature and having a doping level of $6 \%$ atomic, gave the highest piezoelectric parameters: densities of 7.87 and $7.8 \mathrm{~g} / \mathrm{cm}^{3}$, electromechanical coupling factors of 0.665 and 0.638 , dielectric permitivities of 4050 and 3400 and charge constants of 6.25 and $5.30 \mathrm{pm} / \mathrm{V}$ for $\mathrm{Ni}$ and $\mathrm{Fe}$ samples respectively. The Ni doped samples were better than Fe doped ones.

\section{References}

1. Newnham, R.E. \& Ruschan, G.R., Smart electroceramics, $J$. Am. Ceram. Soc., 1991, 74, 463-480.

2. Sporn, D., Watzka, W., Schonecker A \& Pannkoke, K., Smart structures by integrated piezoelectric thin fibers, NATO Sci. Ser; High Techn., 2000, 76, 87-97.

3. Ukino, K., Piezoelectric actuators and ultrasonic motors, Kluwer Acad. Pbls., 1996.

4. Fujita, H., Future of actuators and microsystems, Sensors and Actuators A, 1996, 56, 105-111.

5. Hauden, D., MEMS Application of piezoelectric materials, NATO Sci. Ser; High Techn., 2000, 76, 335-346.

6. Sakai, T., Terai, Y. \& Ishikiriyama, M., Improvement in durability of piezoelectric ceramics for actuators, Jpn. J. Appl. Phys., 1995, 34, 5276-5278.

7. Schuh, C., Lubitz, K., Steinkopff, T. \& Wolf, A., Piezoelectric components for technical applications, NATO Sci. Ser; High Techn., 2000, 76, 391-399.

8. Uchino, K., Piezoelectric ultrasonic motors: overview, Smart Mat. Struct., 1998, 7, 273.

9. Kasuga, M.T., Satoh, N., Tsukada, T., Yamazaki, F., Ogawa, M., Suzuki, I., Horikoshi, T. \& Itoh, T., Compact Ultrasonic Motors, J. Soc. Precision Eng,. 1991, 57, 63-68.

10. Uchino, K. \& Koc, B., Compact piezoelectric Ultrasonic Motors, NATO Sci. Ser; High Techn., 2000, 76, 309-320.

11. Ueha, S. \& Tomikawa, Y., Ultrasonic Motors, Oxford Sci. Pbls., 1993.

12. Wittmer, D.E. \& Buchanan, R.C., Low temperature densification of lead zirconate titanate, J. Am. Cer. Soc., 1981, 64, 485-490.

13. Hankey, D.L. \& Biggers, J.V., Solid state reactions in the system $\mathrm{PbO}-\mathrm{TiO}_{2}-\mathrm{ZrO}_{2}$, J. Am. Cer. Soc., 1981, 64, 172-173.

14. Nielsen, E.R., Ringgaard, E. \& Kosek, M., Liquid phase sintering of PZT, J. Eur. Cer. Soc., 2002, 22, 1847-1855.

15. Jaffe, B., Cook, W.R. \& Jaffe, H., Piezoelectric Ceramics, Acad. Press, London New York, 1971 cp. 7 and 10.

16. Yamamoto, T., Ferroelectric properties of the $\mathrm{PbZrO}_{3}-\mathrm{PbTiO}_{3}$ system, Jpn. J. Appl. Phys., 1996, 35, 5104-5108.

17. Cao, W. \& Cross, L.E., Theoretical model for the morphotropic phase boundary in lead zirconate-lead titanate solid solution, $J$. Am. Phys. Soc. Phys Rev., 1993, 47, 4825-4830. 